\title{
Reversal of Dopamine Inhibition of Dopaminergic Neurons of the Ventral Tegmental Area is Mediated by Protein Kinase C
}

\author{
Sudarat Nimitvilai', Devinder S Arora' and Mark S Brodie*,' \\ 'Department of Physiology and Biophysics, University of Illinois at Chicago, Chicago, IL, USA
}

\begin{abstract}
Adaptation of putative dopaminergic (pDA) neurons in the ventral tegmental area (VTA) to drugs of abuse may alter information processing related to reward and reinforcement and is an important factor in the development of addiction. We have demonstrated that prolonged increases in the concentration of dopamine (DA) result in a time-dependent decrease in sensitivity of pDA neurons to DA, which we termed DA inhibition reversal (DIR). In this study, we used extracellular recordings to examine factors mediating DIR. A 40 min administration of DA (2.5-10 $\mu \mathrm{M})$, but not the DA D2 receptor agonist quinpirole (50-200 nM), resulted in inhibition of neuronal firing followed by DIR. In the presence of $100 \mathrm{nM}$ cocaine, inhibition followed by DIR was seen with much lower DA concentrations. Reversal of quinpirole inhibition could be induced by an activator of protein kinase C, but not of protein kinase A. Inhibitors of protein kinase $C$ or phospholipase $\mathrm{C}$ blocked the development of DIR. Disruption of intracellular calcium release also prevented DIR. Reduction of extracellular calcium or inhibition of store-operated calcium entry blocked DIR, but the L-type calcium channel blocker nifedipine did not. DIR was age-dependent and not seen in pDA VTA neurons from rat pups younger than I 5 days postnatally. Our data indicate that DIR is mediated by protein kinase $\mathrm{C}$, and implicate a conventional protein kinase $\mathrm{C}$. This characterization of DIR gives insight into the regulation of autoinhibition of PDA VTA neurons, and the resulting long-term alteration in information processing related to reward and reinforcement.

Neuropsychopharmacology (2012) 37, 543-556; doi: 10.1 038/npp.201 I.222; published online 5 October 201 I
\end{abstract}

Keywords: dopamine; protein kinase C; ventral tegmental area; desensitization; D2 receptor; D5 receptor

\section{INTRODUCTION}

Changes in dopamine (DA) neurotransmission in the ventral tegmental area (VTA) and its targets have been related to the salience of stimuli, and may play a role in information processing related to reward and reinforcement (Mirenowicz and Schultz, 1996; Schultz, 2010). Increases in dopaminergic neurotransmission are associated with most drugs of abuse (Di Chiara and Imperato, 1988; Imperato and Di Chiara, 1986; Imperato et al, 1986) and may be an important event in reward and reinforcement (Wise, 1996). Dendritic DA release in response to increased activity of mesencephalic DA neurons (Cragg et al, 1997) may affect the excitability of dopaminergic neurons of the VTA. Elevated DA can produce long-term changes in neurotransmission; for example, elevated DA can increase glutamatergic receptor expression in the prefrontal cortex (Gao and Wolf, 2008; Sun et al, 2008).

*Correspondence: Dr MS Brodie, Department of Physiology and Biophysics, University of Illinois at Chicago, 835 South Wolcott, Room E-202, M/C 90 I, Chicago, IL 60612-7342, USA, Tel: + I 3129962373 , Fax: + | 312996 |414, E-mail: mbrodie@uic.edu

Received 7 June 2011; revised 16 August 2011; accepted 24 August 2011
Of the five main classes of DA receptors, the dopaminergic neurons of the VTA possess the 'D1-like' D5 receptors (Ciliax et al, 2000; Khan et al, 2000) and the 'D2-like' receptors D2 (Sesack et al, 1994), D3 (Stanwood et al, 2000), and D4 (Defagot et al, 1997), with D2 predominating. The D1 receptors appear to be on presynaptic glutamatergic terminals projecting to the region rather than on the DA neurons themselves (Caille et al, 1996).

Putative dopaminergic (pDA) neurons of the VTA are spontaneously active in vivo and in vitro, and spontaneous firing is inhibited by the action of DA at D2 autoreceptors on the cell bodies and dendrites of these neurons (Lacey et al, 1987). Stimulation of $\mathrm{D} 2$ receptors on mesencephalic pDA neurons results in the activation of G-protein-coupled inwardly rectifying potassium channels by $\mathrm{G} \beta \gamma$ without the involvement of cAMP or adenylyl cyclase (Kim et al, 1995). Inhibition of firing of pDA VTA neurons by elevation of extracellular DA has been demonstrated by numerous laboratories (Lacey et al, 1987; Brodie and Dunwiddie, 1990); we recently demonstrated that elevation of DA for an extended period of time results in a time- and concentration-dependent decrease in the magnitude of DA-mediated inhibition, a phenomenon that we termed 'DA inhibition reversal (DIR)' (Nimitvilai and Brodie, 2010). This 
desensitization of the DA D2 receptor is dependent on concurrent activation of both D2- and D1-like receptors, requires 10-40 min to develop, and persists for up to $90 \mathrm{~min}$ (Nimitvilai and Brodie, 2010). Therefore, it is neither due purely to homologous desensitization (dependent only on D2 activation) nor to heterologous desensitization (dependent only on activation of a non-D2 receptor). As drugs of abuse are known to increase dopaminergic neurotransmission (by increasing the firing rate of DA neurons or by blocking reuptake of DA at the terminal) (Di Chiara and Imperato, 1988), it is possible that DIR could result from exposure to abused substances. To better understand this phenomenon, we investigated some of the second messenger mechanisms that might contribute to the expression of DIR. For these studies, extracellular recording from pDA VTA neurons in brain slices was used to avoid disrupting the intracellular milieu while monitoring spontaneous firing of pDA VTA neurons for long continuous time periods.

\section{MATERIALS AND METHODS}

\section{Animals}

Fischer 344 (F344; adult rats, 4-6 weeks old, 90-150 g; or rat pups, 12-18 days old) used in these studies were obtained from Harlan Sprague-Dawley (Indianapolis, IN). All rats were treated in strict accordance with the NIH Guide for the Care and Use of Laboratory Animals and all experimental methods were approved by the Animal Care Committee of the University of Illinois at Chicago.

\section{Preparation of Brain Slices}

Brain slices containing the VTA were prepared from the subject animals as described previously (Brodie et al, 1999a). Briefly, following brief isoflurane anesthesia and rapid removal of the brain, the tissue was blocked coronally to contain the VTA and substantia nigra; the cerebral cortices and a portion of the dorsal mesencephalon were removed. The tissue block was mounted in the vibratome and submerged in chilled cutting solution to cut coronal sections ( $400 \mu \mathrm{m}$ thick). An individual slice was placed onto a mesh platform in the recording chamber and was totally submerged in aCSF maintained at a flow rate of $2 \mathrm{ml} / \mathrm{min}$; the temperature in the recording chamber was kept at $35^{\circ} \mathrm{C}$. The composition of the aCSF in these experiments was (in $\mathrm{mM}$ ): $\mathrm{NaCl} 126, \mathrm{KCl} 2.5, \mathrm{NaH}_{2} \mathrm{PO}_{4} 1.24, \mathrm{CaCl}_{2} 2.4, \mathrm{MgSO}_{4}$ $1.3, \mathrm{NaHCO}_{3} 26$, and glucose 11. In some experiments, a low calcium buffer was used; composition of this solution was (in $\mathrm{mM}$ ): $\mathrm{NaCl} 126, \mathrm{KCl} 2.5, \mathrm{NaH}_{2} \mathrm{PO}_{4}$ 1.24, $\mathrm{CaCl}_{2}$ 0.24, $\mathrm{MgSO}_{4} 1.3, \mathrm{NaHCO}_{3} 26$, and glucose 11, adjusted to $\mathrm{pH} 7.4$ with $\mathrm{MgSO}_{4}$. The composition of the cutting solution was (in $\mathrm{mM}$ ): $\mathrm{KCl} 2.5, \mathrm{CaCl}_{2} 2.4, \mathrm{MgSO}_{4} 1.3, \mathrm{NaHCO}_{3} 26$, glucose 11 , and sucrose 220 . Both solutions were saturated with $95 \%$ $\mathrm{O}_{2} / 5 \% \mathrm{CO}_{2}(\mathrm{pH}=7.4)$. Equilibration time of at least $1 \mathrm{~h}$ was allowed after placement of tissue in the recording chamber before electrodes were placed in the tissue.

\section{Cell Identification}

The VTA was clearly visible in the fresh tissue as a gray area medial to the darker substantia nigra, and separated from the nigra by white matter. Recording electrodes were placed in the VTA under visual control. pDAergic neurons have been shown to have distinctive electrophysiological characteristics (Grace and Bunney, 1984; Lacey et al, 1989). Only those neurons that were anatomically located within the VTA and which conformed to the criteria for pDAergic neurons established in the literature and in this laboratory (Lacey et al, 1989; Mueller and Brodie, 1989) were studied. These criteria include broad action potentials $(2.5 \mathrm{~ms}$ or greater, measured as the width of the bi- or tri-phasic waveform at the baseline), slow spontaneous firing rate $(0.5-5 \mathrm{~Hz})$, and a regular interspike interval. Cells were not tested with opiate agonists as has been done by other groups to further characterize and categorize VTA neurons (Margolis et al, 2006). It should be noted that some neurons with the characteristics we used to identify DA VTA neurons may not, in fact, be DA-containing (Margolis et al, 2006). For this reason, we refer to the neurons recorded in this study as pDA VTA neurons.

Additional characterization, such as determining the projection target of our cells of study (Margolis et al, 2008), would have been difficult as we have used extracellular recording to insure high-quality, long-duration recordings. The long-duration, low-frequency action potentials that characterized the cells from which we recorded are associated with DA-sensitive, DA-containing neurons projecting to the nucleus accumbens, and DA sensitivity also is associated with DA VTA neurons projecting to the prefrontal cortex (Margolis et al, 2008). One consequence of differential initial sensitivity to DA inhibition among groups of neurons projecting to different brain areas (Margolis et al, 2008; Lammel et al, 2008) would be different amounts of DIR (Nimitvilai and Brodie, 2010), resulting in a greater relative change in neurons more sensitive to DA inhibition.

\section{Drug Administration}

In most experiments, drugs were added to the aCSF by means of a calibrated infusion pump from stock solutions 100-1000 times the desired final concentrations. The addition of drug solutions to the aCSF was performed in such a way as to permit the drug solution to mix completely with aCSF before this mixture reached the recording chamber. Final concentrations were calculated from aCSF flow rate, pump infusion rate and concentration of drug stock solution. The small volume chamber (about $300 \mu \mathrm{l}$ ) used in these studies permitted the rapid application and washout of drug solutions. Typically drugs reach equilibrium in the tissue after 2-3 min of application.

In some experiments, drugs were added to the microelectrode filling solution $(0.9 \% \mathrm{NaCl})$ at a concentration about 10 times greater than that which would have been used in the extracellular medium. To allow time for the drug to diffuse from the pipette to the cell, the effects of bath-applied drugs were tested no $<20 \mathrm{~min}$ after initiating the recording; this pipette-application method has produced comparable results to the administration of drugs through the extracellular medium in the cases in which both methods were tested (data not shown), with the advantage of more localized application and reduced expense. One disadvantage of this method is that the exact concentration 
of drug received by the neurons from which we recorded is unknown.

DA hydrochloride, quinpirole, and most of the salts used to prepare the extracellular media were purchased from Sigma (St Louis, MO). Forskolin, 8-bromo cyclic AMP, phorbol 12-myristate 13-acetate (PMA), bisindolylmaleimide-I (BIS-I), Gö6976 (5,6,7,13-tetrahydro-13-methyl-5-oxo-12H-indolo [2,3a]pyrrolo[3,4-c]carbazole-12-propanenitrile), protein kinase $\mathrm{C}$ (PKC) $\beta$ inhibitor (3-(1-(3-imidazol-1-ylpropyl)-1H-indol3-yl)-4-anilino-1H-pyrrole-2,5-dione), nifedipine, caffeine, SKF96365 (1-[2-(4-methoxy-phenyl)-2-[3-(4-methoxyphenyl) propoxy]ethyl- $1 \mathrm{H}$-imidazole hydrochloride), thapsigargin, chelerythrine chloride, ryanodine, 2-aminoethoxydiphenyl borate (2-APB), and U73122 were purchased from Tocris (Ellisville, MO). (-) Cocaine $\mathrm{HCl}$ was purchased from Research Biochemicals (Natick, MA).

\section{Extracellular Recording}

Extracellular recording was chosen for these studies as this method permits the recordings to be of long duration and allows us to assess the effects of extended exposure ( $>30 \mathrm{~min}$ ) to drugs. The limitation of only measuring spontaneous action potential frequency (rather than membrane potential or other electrophysiological parameters) is counterbalanced by the advantage of being able to determine the time course of drug actions and interactions. Extracellular recording electrodes were made from $1.5 \mathrm{~mm}$ diameter glass tubing with filament and were filled with $0.9 \% \mathrm{NaCl}$. Tip resistance of the microelectrodes ranged from 2 to $4 \mathrm{M} \Omega$. A Fintronics amplifier was used in conjunction with an IBM-PC-based data-acquisition system (ADInstruments, Colorado Springs, CO). Offline analysis was used to calculate, display, and store the frequency of firing in $1 \mathrm{~min}$ intervals. Additional software was used to calculate the firing rate over $5 \mathrm{~s}$ intervals. Firing rate was determined before and during drug application. Firing rate was calculated over $1 \mathrm{~min}$ intervals before administration of drugs and during the drug effect; peak drug-induced changes in firing rate were expressed as the percentage change from the control firing rate according to the formula $((\mathrm{FRD}-\mathrm{FRC}) / \mathrm{FRC}) \times 100$, where $\mathrm{FRD}$ is the firing rate during the peak drug effect and FRC is the control firing rate. The change in firing rate thus is expressed as a percentage of the initial firing rate, which controls for small changes in firing rate that may occur over time. This formula was used to calculate both excitatory and inhibitory drug effects. Peak excitation produced by the drug (eg, DA) was defined as the peak increase in firing rate over pre-drug baseline. Inhibition was defined as the lowest firing rate below the pre-drug baseline. Inhibition reversal was identified as a statistically significant reduction in the inhibition.

\section{Data Collection}

For comparison of the time course of effects on firing rate, the data were normalized and averaged. Firing rates over $1 \mathrm{~min}$ intervals were calculated and normalized to the $1 \mathrm{~min}$ interval immediately before DA administration. These normalized data were averaged by synchronizing the data to the DA administration period, and graphs of the averaged data were made.

\section{Statistical Analysis}

Averaged numerical values were expressed as the mean \pm the standard error of the mean (SEM). Mean response graphs are shown as relative change in firing rate, to normalize the response to the inhibition observed in the first $5 \mathrm{~min}$ interval; mean percentage inhibition as a function of baseline firing rate is indicated in the text. The differences among firing rates during the long drug administration intervals in these studies was assessed with repeated measures ANOVA; degrees of freedom and statistical error terms are shown as subscripts to $F$ in the text (Kenakin, 1987). Statistical analyses were performed with OriginPro 8.5 (OriginLab, Northampton, MA).

\section{RESULTS}

\section{VTA Neuron Characteristics}

A total of 285 VTA neurons were examined. Their firing rate in normal extracellular medium ranged from 0.61 to $4.56 \mathrm{~Hz}$, with a mean of $1.85 \pm 0.05 \mathrm{~Hz}$. All neurons had regular firing rates and were inhibited by DA. Sensitivity to DA $(0.5-5 \mu \mathrm{M})$ was initially assessed by administering the agonist for $5 \mathrm{~min}$, and then washing it out until the baseline firing rate recovered; quinpirole $(25-200 \mathrm{nM})$ was administered for $5 \mathrm{~min}$, and the concentration was increased if inhibition $>50 \%$ was not achieved. The concentrations of agonist were adjusted for each neuron so that inhibition exceeded $50 \%$, as inhibition that was $<50 \%$ was not reliably reversed (Nimitvilai and Brodie, 2010). This method of adjusting the concentration of dopaminergic agonist controlled for differences in sensitivity between neurons, but also sometimes resulted in the mean concentrations of DA or quinpirole slightly differing between groups. Overall, for pDA VTA neurons from adult rats (not including cells tested with DA in the presence of cocaine), the concentration of DA used was $6.2 \pm 0.3 \mu \mathrm{M}(n=92)$, which produced a mean change in firing rate of $-68.1 \pm 1.3 \%$; the concentration of quinpirole used was $52.6 \pm 2.2 \mathrm{nM}(n=25)$, which produced a mean change in firing rate of $-73.6 \pm 2.2 \%$. For the rat pups used in these experiments, $7.6 \pm 0.6 \mu \mathrm{M}(n=66)$ DA was used to produce a change in firing rate of $-71.0 \pm 1.9 \%$. There were no significant differences in the concentration of dopaminergic agonist or in the percentage inhibition between the groups (one-way ANOVA, $p>0.05$ ). In most experiments, as blockers of the DA transporter were not used, there is normally sufficient DA release in brain slices to cause complete cessation of spontaneous firing in the presence of DA transporter blockers (Brodie and Dunwiddie, 1990). In the absence of DA transporter blockers, DA produces inhibitory effects at concentrations ranging from 0.5 to $100 \mu \mathrm{M}$, although in dissociated DA VTA neurons, concentrations as low as $50 \mathrm{nM}$ can completely inhibit spontaneous action potential firing (Brodie et al, 1999b). Cells that did not return to at least $70 \%$ of their pre-DA firing rate during this washout were not used. One benefit of the extracellular recording method used in these studies is that long duration recordings can be 
Table I

\begin{tabular}{|c|c|c|c|c|c|c|}
\hline Chemical name & $\begin{array}{l}\text { Chemical conc. }(\mu \mathrm{M}) \\
\text { (in delivery tubing) }\end{array}$ & $\begin{array}{l}\text { No. of } \\
\text { cells }\end{array}$ & $\begin{array}{l}\text { Mean firing rate } \\
\text { at baseline }(\mathrm{Hz})\end{array}$ & $\begin{array}{l}\text { Mean firing rate } \\
\text { at } 20 \mathrm{~min}(\mathrm{~Hz})\end{array}$ & $\begin{array}{l}\text { Mean firing rate } \\
\text { at } 55 \mathrm{~min}(\mathrm{~Hz})\end{array}$ & $P$-value \\
\hline Forskolin & 2.5 & 5 & $2.18 \pm 0.6$ & $2.32 \pm 1.5$ & $2.19 \pm 0.6$ & $>0.05$ \\
\hline PMA & 0.1 & 5 & $2.08 \pm 0.4$ & $1.87 \pm 0.6$ & $1.77 \pm 0.2$ & $>0.05$ \\
\hline $\mathrm{PKC} \beta$ inhibitor & । & 5 & $1.75 \pm 0.2$ & $1.73 \pm 0.4$ & $1.79 \pm 0.2$ & $>0.05$ \\
\hline Chelerythrine & 10 & 4 & $2.66 \pm 0.3$ & $2.56 \pm 0.7$ & $2.75 \pm 0.4$ & $>0.05$ \\
\hline U73122 & 2 & 8 & $2.27 \pm 0.3$ & $2.27 \pm 0.9$ & $2.08 \pm 0.3$ & $>0.05$ \\
\hline Ryanodine & 10 & 5 & $0.97 \pm 0.1$ & $0.86 \pm 0.2$ & $0.90 \pm 0.03$ & $>0.05$ \\
\hline 2-APB & 10 & 7 & $2.03 \pm 0.3$ & $1.87 \pm 0.9$ & $1.77 \pm 0.4$ & $>0.05$ \\
\hline SKF96365 & 100 & 5 & $2.88 \pm 0.3$ & $2.79 \pm 0.8$ & $2.68 \pm 0.3$ & $>0.05$ \\
\hline Thapsigargin & 30 & 9 & $1.04 \pm 0.1$ & $1.0 \pm 0.38$ & $1.07 \pm 0.1$ & $<0.05$ \\
\hline
\end{tabular}

made reliably; the average recording duration was $71.5 \pm 0.7 \mathrm{~min}$, with a range of $55-90 \mathrm{~min}$.

In the course of performing the experiments described below, we used a number of pharmacological agents, delivered either via the extracellular medium or via the recording pipette, and these agents were applied for 15-20 min before the $40 \mathrm{~min}$ administration of either quinpirole or DA. In separate experiments, we tested whether these agents alone altered the firing rate of $\mathrm{pDA}$ VTA neurons. The results of these control experiments are shown in Table 1; the firing rates shown in the table are the pre-drug baseline, the firing rate at a time point equivalent to the $5 \mathrm{~min}$ time point of DA agonist administration, and the firing rate at a time point equivalent to the $40 \mathrm{~min}$ time point at the end of DA agonist administration. In brief, in the concentrations applied in the experiments described below, most of the agents did not significantly alter the firing rate of the neurons tested between the equivalents of the 5 and $40 \mathrm{~min}$ time point (one-way repeated measures ANOVA, $p>0.05$ for all groups). Two exceptions to this are BIS-I, which produced a small but significant decrease in firing with time and thapsigargin, which produced a small but significant increase in firing with time (one-way repeated measures ANOVA, $P<0.05)$.

\section{DIR Occurs at Low DA Concentrations in Cocaine}

Reversal of DA inhibition with time occurs with DA but not with quinpirole, as reported previously (Nimitvilai and Brodie, 2010). We extended this observation to determine if the same phenomenon occurred in the presence of a low concentration of cocaine ( $100 \mathrm{nM}$; Figure 1). Figures 1a-d illustrate data from single neurons, and the pooled data in Figure 1e are presented normalized to the firing rate at the 5 min time point for clarity. A concentration of DA was chosen that inhibited the firing rate by $60-80 \%$, and this concentration was applied in the superfusate for $40 \mathrm{~min}$.
As in our previous study, DA $(6.1 \pm 1.4 \mu \mathrm{M} ; n=7)$ produced $80 \%$ inhibition at $5 \mathrm{~min}$, and at $40 \mathrm{~min}$ there was significant reduction in this inhibition, illustrated as a relative increase in firing rate of $31.7 \pm 3.8 \%$ compared to the $5 \mathrm{~min}$ time point, which is indicative of DIR (one-way repeated measures ANOVA, $F_{(7,42)}=34.42, P<0.01$; Figures $1 \mathrm{a}$ and $e$ ). In the presence of $100 \mathrm{nM}$ cocaine, only $0.88 \pm 0.25 \mu \mathrm{M} \mathrm{DA}$ was needed to achieve $77.9 \pm 5.1 \%$ inhibition at $5 \mathrm{~min}$, which showed a similar reversal trajectory over time to that of higher DA, so that at $40 \mathrm{~min}$, there was a relative increase in firing rate of $32.7 \pm 13.6 \% \quad(n=8$; one-way repeated measures ANOVA, $F_{(7,49)}=19.61, P<0.01$; Figures $1 \mathrm{~b}$ and e). In the absence of cocaine, $0.88 \mu \mathrm{M}$ DA produced $9.29 \pm 3.0 \%$ inhibition at $5 \mathrm{~min}$, which by the end of $40 \mathrm{~min}$ had a relative decrease of $6.4 \pm 3.0 \%$ (Figures $1 \mathrm{c}$ and e), which was statistically different from the 5 min time point $(n=8$; one-way repeated measures ANOVA, $\left.\mathrm{F}_{(7,70)}=4.61, P<0.01\right)$. In an additional experiment, $100 \mathrm{nM}$ cocaine alone (Figure 1d) was added to the superfusate for a total of $55 \mathrm{~min}$, a time period equivalent to the $15 \mathrm{~min}$ pre-incubation period plus the $40 \mathrm{~min}$ period during which DA would have been administered (as in Figure $1 \mathrm{~b}$ ). Cocaine alone produced a small but significant decrease in firing rate over the course of the last $40 \mathrm{~min}$ of the administration $(n=8$; one-way repeated measures ANOVA, $\left.\mathrm{F}_{(11,77)}=5.93, P<0.01\right)$. The results of these experiments indicate that cocaine not only potentiates the inhibitory effect of DA (Brodie and Dunwiddie, 1990), but also increases the likelihood that low DA concentrations can produce desensitization of pDA VTA neurons to DA.

\section{Activators of PKC but not of PKA Reverse Quinpirole Inhibition of Firing}

We have demonstrated previously that quinpirole-induced inhibition was sustained over a $40 \mathrm{~min}$ application period and did not reverse except in the presence of a D1/D5 

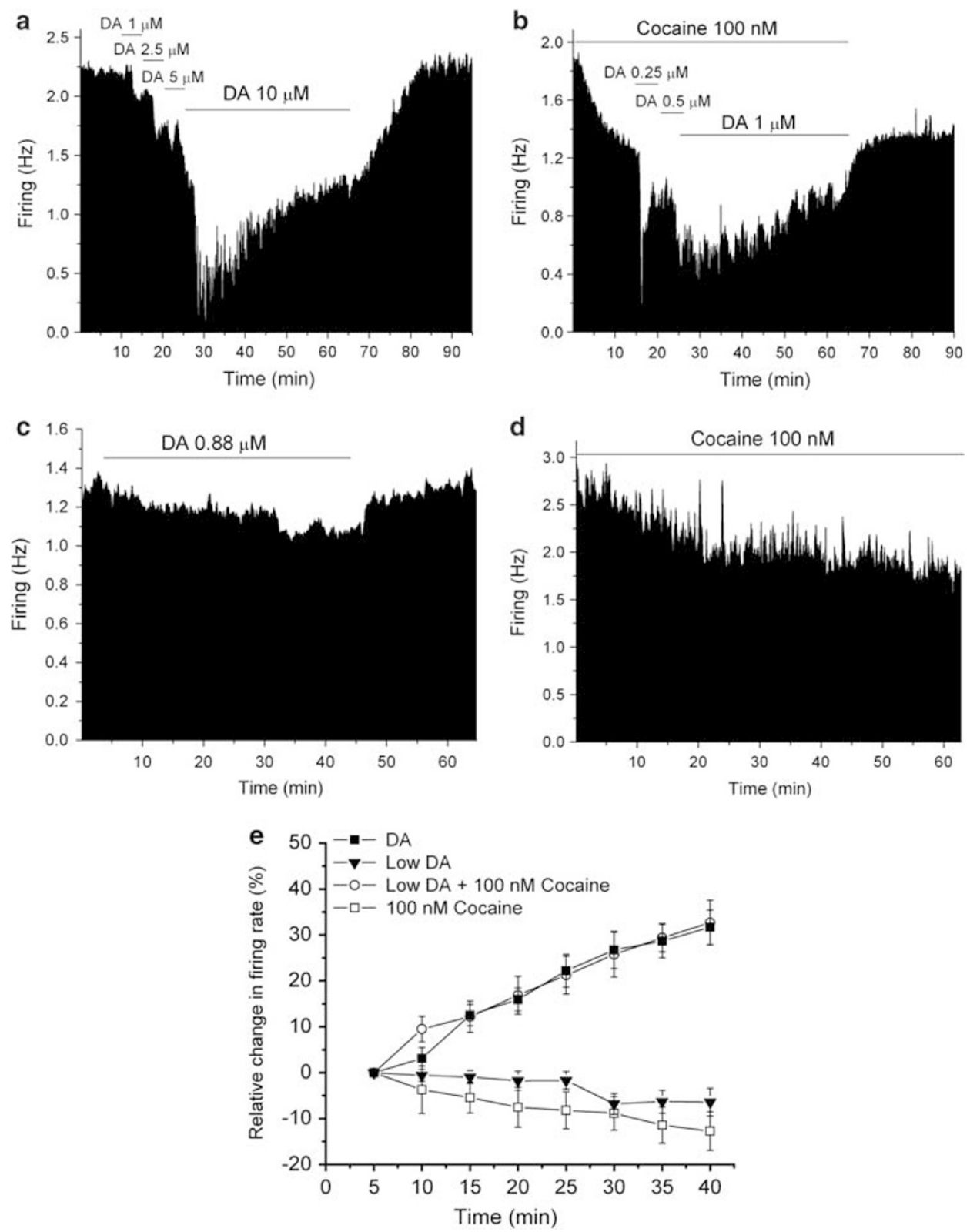

Figure I Effect of cocaine on long-duration dopamine (DA) application. (a-d) Mean ratemeter graphs of the effects of long-duration application of DA and cocaine in single neurons. Vertical bars indicate the firing rate over 5 s intervals. Horizontal bars indicate the duration of drug application (concentrations indicated above bar). (a) DA alone (final test concentration $10 \mu \mathrm{M}$ ) produced a decrease in firing rate of $83.0 \%$, which subsided over time so that the inhibition at $40 \mathrm{~min}$ (compared with control firing rate) was $41.6 \%$. (b) In the presence of $100 \mathrm{nM}$ cocaine, DA (I $\mu$ M) produced a $65.9 \%$ inhibition at 5 min, and this inhibition also subsided over time so that the inhibition at 40 min was $29.5 \%$. (c) The mean concentration of DA used in the group of experiments similar to that shown in (b) was $0.88 \mu \mathrm{M}$; this concentration of DA given for 40 min produced a maximum decrease in firing rate of $16.8 \%$, with no appreciable reversal. (d) A 40 min application of $100 \mathrm{nM}$ cocaine alone produced a decrease in firing of $31.2 \%$, with no appreciable reversal. (e) Relative change in firing rate (mean \pm SEM) is plotted as a function of time. In experiments similar to those shown in parts a-d above, the effect of DA at each time point was normalized by subtracting the change in firing rate (\%) at the 5 min time point. A concentration of DA that produced more than $60 \%$ inhibition at $5 \mathrm{~min}$ time point was applied for $40 \mathrm{~min}(\boldsymbol{\square})$. DA ([DA] $=6.1 \pm 1.4 \mu \mathrm{M}(n=7))$ inhibition of firing rate at 5 min was followed by a significant decrease in $\mathrm{DA}$-induced inhibition over time (one-way repeated measures analysis of variance (ANOVA), $\left.F_{(7,42)}=34.42, P<0.0 \mathrm{I}\right)$. In the presence of cocaine $(\mathrm{I} 00 \mathrm{nM}$, $O)$, a much lower concentration of $D A([D A]=0.88 \pm 0.7 \mu M, n=8)$ also showed significant reversal of DA inhibition over time (one-way repeated measures ANOVA, $\left.F_{(7,49)}=19.61, P<0.0 I\right)$. In the absence of cocaine, a low concentration of DA $(0.88 \mu M, n=1 \mathrm{I}, \boldsymbol{\nabla})$ produced a small but significant decrease in firing rate, in that the last three time points were significantly different from the 5 min time point (one-way repeated measures ANOVA, $\left.\mathrm{F}_{(7,70)}=4.6 \mathrm{I}, P<0.0 \mathrm{I}\right)$. In the absence of applied DA, $100 \mathrm{nM}$ cocaine $(n=8, \square)$ produced a small but significant decrease in firing rate, in that the last two time points were significantly different from the $5 \mathrm{~min}$ time point (one-way repeated measures $A N O V A, F_{(I I, 77)}=4.61, P<0.01$ ).

agonist (Nimitvilai and Brodie, 2010). As D1/D5 and D2 receptors have been linked to the activation and inhibition of the adenylyl cyclase second messenger system, we tested whether quinpirole inhibition was reversed in the presence of forskolin $(2.5 \mu \mathrm{M})$ or 8-bromo-cAMP $(100 \mu \mathrm{M})$. As there is evidence of physiological functions of PKC in pDA VTA neurons (Liu et al, 2003), we also tested whether quinpiroleinduced inhibition was reversed in the presence of an 
activator of PKC, PMA (100 nM). The results of these experiments are shown in Figure 2; Figures 2a-d illustrate data from single neurons, and the pooled data in Figure $2 \mathrm{e}$ are presented normalized to the effect of quinpirole from each group at the $5 \mathrm{~min}$ time point for clarity. Similar to our previous study (Nimitvilai and Brodie, 2010), administration of quinpirole for $40 \mathrm{~min}(n=7)$ inhibited the firing of pDA VTA neurons and showed no reduction of that inhibition for the duration of the $40 \mathrm{~min}$ application (Figures 2a and e). Comparison of inhibition at $5 \mathrm{~min}$ intervals over the $40 \mathrm{~min}$ period of drug exposure was normalized to the value measured at the first $5 \mathrm{~min}$ time
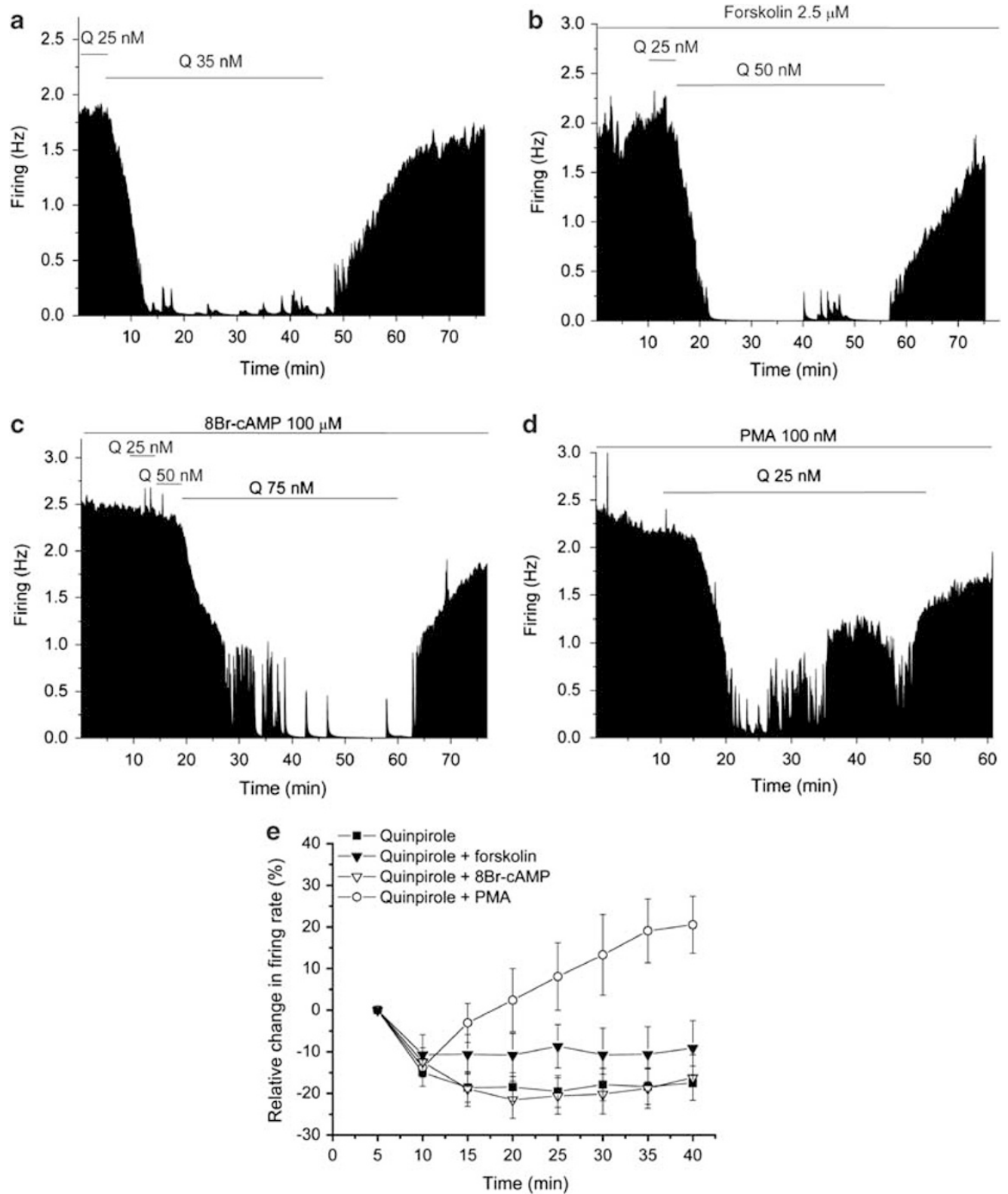

Figure 2 Effects of activators of protein kinase $A$ and protein kinase $C$ on long-duration quinpirole application. (a-d) Mean ratemeter graphs of the effects of protein kinase activators on long-duration quinpirole administration in single neurons. Vertical bars indicate the firing rate over $5 \mathrm{~s}$ intervals. Horizontal bars indicate the duration of drug application (concentrations indicated above bar). Quinpirole (Q) alone (a) produced an inhibition of firing rate for the duration of quinpirole application, and the firing resumed after washout of the quinpirole. In the presence of either forskolin (b) or 8-bromo-cAMP (c), there was no change in quinpirole-induced inhibition. In the presence of the phorbol ester PMA (d), a decrease in quinpirole inhibition was observed over the time course of quinpirole application. (e) Relative change in firing rate (mean \pm SEM) in response to long-duration quinpirole application in the absence or presence of protein kinase activators is plotted as a function of time. Effect of quinpirole at each time point was normalized by subtracting the change in firing rate (\%) at the $5 \mathrm{~min}$ time point. A concentration of quinpirole that after 5 min produced $50 \%$ inhibition or greater was applied for 40 min. Quinpirole alone ( . [quinpirole] $=40 \pm 5.1 \mathrm{nM}, n=7$ ) produced inhibition of the firing rate, which showed a significant decrease over the 40 min duration of quinpirole application (one-way repeated measures analysis of variance (ANOVA), $F=16.68, P<0.01$ ). A significant increase in quinpirole inhibition was observed over time in the presence of $2.5 \mu \mathrm{M}$ forskolin $(\boldsymbol{\nabla}$. [quinpirole] $=72.43 \pm 15.8 \mathrm{nM}, n=7$ ) (one-way repeated measures $A N O V A, F=2.58, P<0.05)$ and in the presence of $100 \mu \mathrm{M}$ 8-bromo-cAMP $(\nabla$, [quinpirole] $=60 \pm 9.6 \mathrm{nM}, n=6$ ) (one-way repeated measures $A N O V A, F=7.04, P<0.0 \mathrm{I}$ ). In the presence of $100 \mathrm{nM}$ PMA, there was a significant reduction in quinpirole inhibition over time ( $O$, [quinpirole] $=35 \pm 10 \mathrm{nM}, n=5$ ), with the last three time points significantly different from the 10 min time point (one-way repeated measures $A N O V A, F=7.18, P<0.00 I$; Tukey's post-hoc test, $P<0.05$ ). 
point and showed that there was a significant decrease in firing rate over the duration of quinpirole application (repeated measures ANOVA $\mathrm{F}_{(7,42)}=16.68, P<0.01$ ). Since DA receptors are coupled to adenylyl cyclase, we tested the effect of forskolin and 8-bromo-cAMP on quinpirolemediated inhibition of firing. Administration of quinpirole $(n=7)$ with $2.5 \mu \mathrm{M}$ forskolin produced a similar pattern of inhibition as control (Figures $2 \mathrm{~b}$ and e) and comparison of firing rates at $5 \mathrm{~min}$ intervals showed a significant decrease in firing rate over the $40 \mathrm{~min}$ period of drug exposure (repeated measures ANOVA $\mathrm{F}_{(7,42)}=2.58$, $P<0.05)$. Similarly, co-administration of 8-bromo-cAMP $(100 \mu \mathrm{M})$ and quinpirole $(n=6)$ produced similar inhibition (Figures $2 \mathrm{c}$ and e); again, comparison of the inhibition at $5 \mathrm{~min}$ intervals indicated a significant decrease in firing rate from the 5 min time point (repeated measures ANOVA, $\left.\mathrm{F}_{(7,35)}=7.04, P<0.01\right)$.

Since pDA VTA neurons are regulated by PKC (Liu et al, 2003; Luu and Malenka, 2008), we investigated if activation of PKC alters the effect of quinpirole. In the presence of the PKC activator PMA ( $100 \mathrm{nM})$, quinpirole $(n=5$; Figures $2 \mathrm{~d}$ and e) inhibition declined significantly over time after 10 min, reaching a firing rate $20 \%$ greater than the firing rate at the $5 \mathrm{~min}$ time point by the end of the $40 \mathrm{~min}$ period of drug exposure (repeated measures ANOVA, $\mathrm{F}_{(7,28)}=7.18$, $P<0.001$ ), and a Tukey's post-hoc comparison indicated a significant difference between rates measured at $10 \mathrm{~min} v \mathrm{~s}$ 30,35 , or $40 \mathrm{~min}(P<0.05)$. PMA alone had no significant effect on firing (Table 1), so the reversal of quinpirole inhibition was not due simply to an additive effect of PMA and quinpirole. These results suggest that PKC, but not PKA, antagonizes the inhibitory effect of quinpirole on pDA VTA neuron firing.

\section{PKC Inhibitors Prevent Reversal of DA Inhibition of Firing}

To confirm the importance of PKC in dopaminergic regulation of pDA VTA firing, we co-administered DA with PKC inhibitors and measured firing rates every $5 \mathrm{~min}$, normalizing the results to firing measured after the first $5 \mathrm{~min}$ of drug exposure (Figure 3). The general PKC inhibitors BIS-I and chelerythrine, and the conventional PKC inhibitor Gö6976 prevented the reversal of DA inhibition of firing. In the presence of BIS-I, chelerythrine, or Gö6976, reversal of DA-induced inhibition was not observed. The inhibition produced by DA in the presence of each PKC inhibitor at $5 \mathrm{~min}$ intervals was compared using a one-way repeated measures ANOVA. There was no significant change produced by DA when BIS-I (repeated measures, $\mathrm{F}_{(7,42)}=0.64, P>0.05$ ) or chelerythrine (repeated measures, $\left.\mathrm{F}_{(7,49)}=1.35, P>0.05\right)$ was present in the superfusate. Co-application of DA and Gö6976 produced a significant decrease in firing rate over the time course (repeated measures ANOVA, $\mathrm{F}_{(7,28)}=11.23, P<0.01$ ). In the presence of $\mathrm{PKC} \beta$ inhibitor (3-(1-(3-imidazol1-ylpropyl)-1 $H$-indol-3-yl)-4-anilino- $1 H$-pyrrole-2,5-dione, $1 \mu \mathrm{M} ; n=7)$, however, DA did produce a significant reversal of DA-induced inhibition over the duration of drug administration (repeated measures ANOVA, $\mathrm{F}_{(7,35)}=8.01$, $P<0.01)$ These results implicate the involvement of a

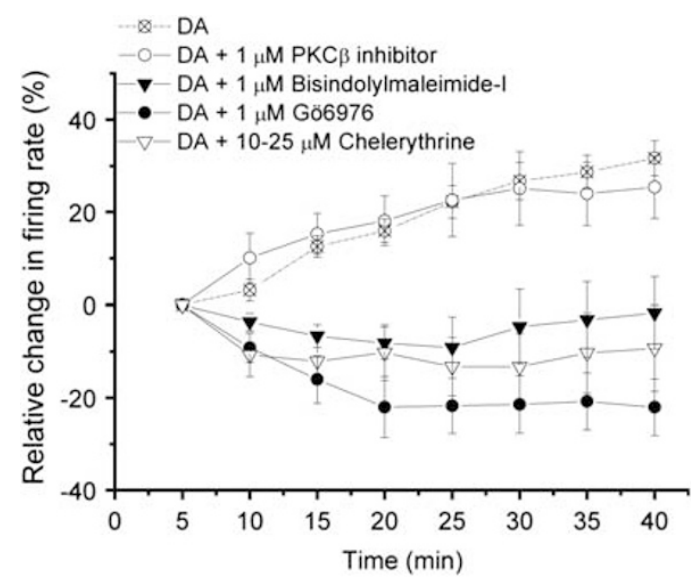

Figure 3 Effects of protein kinase $C$ inhibitors on long-duration dopamine (DA) application. Relative change in firing rate (mean \pm SEM) is plotted as a function of time. Effect of DA at each time point was normalized by subtracting the change in firing rate (\%) at the 5 min time point. A concentration of DA that after 5 min produced more than $60 \%$ inhibition was applied for $40 \mathrm{~min}$ alone $(\boldsymbol{\square},[\mathrm{DA}]=6.1 \pm 1.4 \mu \mathrm{M} ; n=7)$, or in the presence of $10-25 \mu \mathrm{M}$ chelerythrine $(\nabla,[\mathrm{DA}]=4.75 \pm 1.26 \mu \mathrm{M}$; $n=8), \quad \mid \mu M$ bisindolylmaleimide-I (BIS-I) $(\nabla, \quad[D A]=8.57 \pm 0.74 \mu \mathrm{M}$; $n=7), \quad$ I $\mu \mathrm{M}$ Gö6976 (5,6,7,13-tetrahydro-13-methyl-5-oxo- $12 \mathrm{H}$ indolo[2,3-a]pyrrolo[3,4-c]carbazole- I2-propanenitrile) $(\bullet,[D A]=4.9 \pm$ I.62 $\mu \mathrm{M} ; n=5)$, or I $\mu \mathrm{M}$ PKC $\beta$ inhibitor $(O,[D A]=4.33 \pm 1.3 \mu \mathrm{M} ; n=6)$. The effect of DA alone is shown for comparison (open symbol and dashed line, data from Figure I for reference only). DA produced inhibition in firing rate without a significant reversal when BIS-I (one-way repeated measures analysis of variance (ANOVA), $F=0.64, P>0.05$ ) or chelerythrine (one-way repeated measures ANOVA, $F=1.35, P>0.05$ ) was present. In the presence of Gö6976, DA produced a significant increase of inhibition in firing rate over the $40 \mathrm{~min}$ time course (one-way repeated measures ANOVA, $F=\mid 1.23, P<0.01$ ). In contrast, in the presence of the PKC $\beta$ inhibitor, a significant reduction in DA-induced inhibition over the $40 \mathrm{~min}$ time course was observed (one-way repeated measures ANOVA, $\mathrm{F}=8.0 \mathrm{I}, \mathrm{P}<0.0 \mathrm{I})$.

conventional isoform of PKC in mediating DIR, but not $\operatorname{PKC} \beta$.

\section{DIR: Dependence on Phospholipase C}

The classical mechanism for activation of PKC is through the phospholipase C (PLC) pathway. In addition, concomitant activation of either D1-D2 or D5-D2 receptors have been demonstrated to stimulate Gq and PLC (Lee et al, 2004; So et al, 2005; Rashid et al, 2007). For these reasons, we examined the action of a PLC inhibitor, U73122, on DIR. In the presence of U73122 $(2 \mu \mathrm{M})$, there was no reduction of DA inhibition $(n=8)$ over the $40 \mathrm{~min}$ application period (one-way repeated measures ANOVA, $\mathrm{F}_{(7,49)}=1.55$; $P>0.05$ ), indicating a blockade of DIR (Figure 4).

\section{DIR: Dependence on Calcium}

Since Gö6976 blocked reversal of DA inhibition, it is likely that a conventional PKC mediates this effect. $\mathrm{PKC} \alpha, \operatorname{PKC} \beta$, and $\mathrm{PKC} \gamma$ comprise the conventional PKC subfamily, and among all other PKC isozymes, these isozymes are unique in that they can be activated by calcium (Akita et al, 1990). Therefore, we investigated if reversal of DA inhibition was calcium-dependent. Activation of PLC triggers the release of 


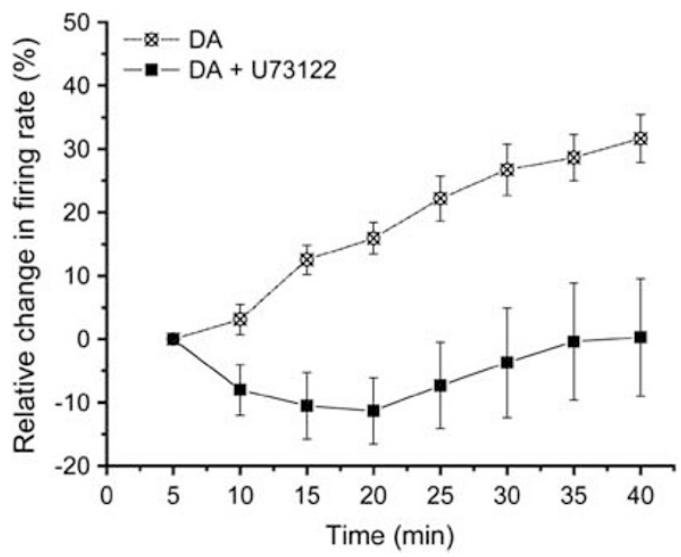

Figure 4 Effect of phospholipase $C$ inhibitor on long-duration dopamine (DA) application. Relative change in firing rate (mean \pm SEM) is plotted as a function of time. Effect of DA at each time point was normalized by subtracting with the change in firing rate (\%) at the 5 min time point. The response to a concentration of DA that produced reversal of DAinduced inhibition (from Figure I) is shown for reference (open symbols and dashed line). A concentration of DA that produced more than $60 \%$ inhibition at $5 \mathrm{~min}$ time point was applied for $40 \mathrm{~min}$. In the presence of phospholipase C (PLC) inhibitor U73I22 (2 $\mu \mathrm{M})$, there was no significant change in the inhibition produced by $\mathrm{DA}$ ( $[\mathrm{DA}]=7.8 \pm 0.7 \mu \mathrm{M}, n=8$ ) over the time course (one-way repeated measures analysis of variance (ANOVA), $F=1.55, P>0.05$ ).

calcium from intracellular stores via stimulation of inositol 1,4,5-triphosphate (IP3) receptors. To determine the importance of calcium release from intracellular stores to DIR, the development of DIR was assessed in the presence of IP3 receptor inhibitor 2-APB $(10 \mu \mathrm{M})$. With 2-APB, no reversal of DA inhibition $(n=5)$ was observed (oneway repeated measures ANOVA, $\mathrm{F}_{(7,28)}=0.26 ; P>0.05$; Figure 5a). We also tested whether ryanodine receptors were involved in DIR. Ryanodine acts at ryanodine receptors as either an agonist or antagonist, depending on the concentration, and induces persistent inactivation of the ryanodine receptor at concentrations $>100 \mathrm{nM}$ (Zimanyi et al, 1992; Buck et al, 1992). In the presence of ryanodine $(10 \mu \mathrm{M})$, DA inhibition in firing rate did not reverse, but the inhibition increased over the $40 \mathrm{~min}$ time course $(n=6$; one-way repeated measures ANOVA, $\mathrm{F}_{(7,35)}=4.43 ; P<0.01$; Figure 5a).

Additional studies were performed to determine the involvement of intracellular calcium stores in the development of DIR. High concentrations of caffeine affect intracellular calcium stores by causing release of calcium via activation of the ryanodine receptor (Guerreiro et al, 2011). Thapsigargin causes depletion of calcium from intracellular stores by inhibiting the endoplasmic reticulum $\mathrm{Ca}^{2+}$-ATPase (Bian et al, 1991). To determine the importance of intracellular calcium stores to DIR, caffeine $(5 \mathrm{mM})$ was added to the extracellular medium at least $1 \mathrm{~h}$ before recordings were performed. In the presence of $5 \mathrm{mM}$ caffeine, there was a significant decrease in firing rate produced by DA over the $40 \mathrm{~min}$ administration period $\left(n=5\right.$; repeated measures ANOVA, $\left.\mathrm{F}_{(7,35)}=9.74, P<0.01\right)$, indicating a blockade of DIR (Figure $5 \mathrm{a}$ ). Likewise, there was no significant reversal of DA-induced inhibition when thapsigargin was present over the $40 \mathrm{~min}$ application period
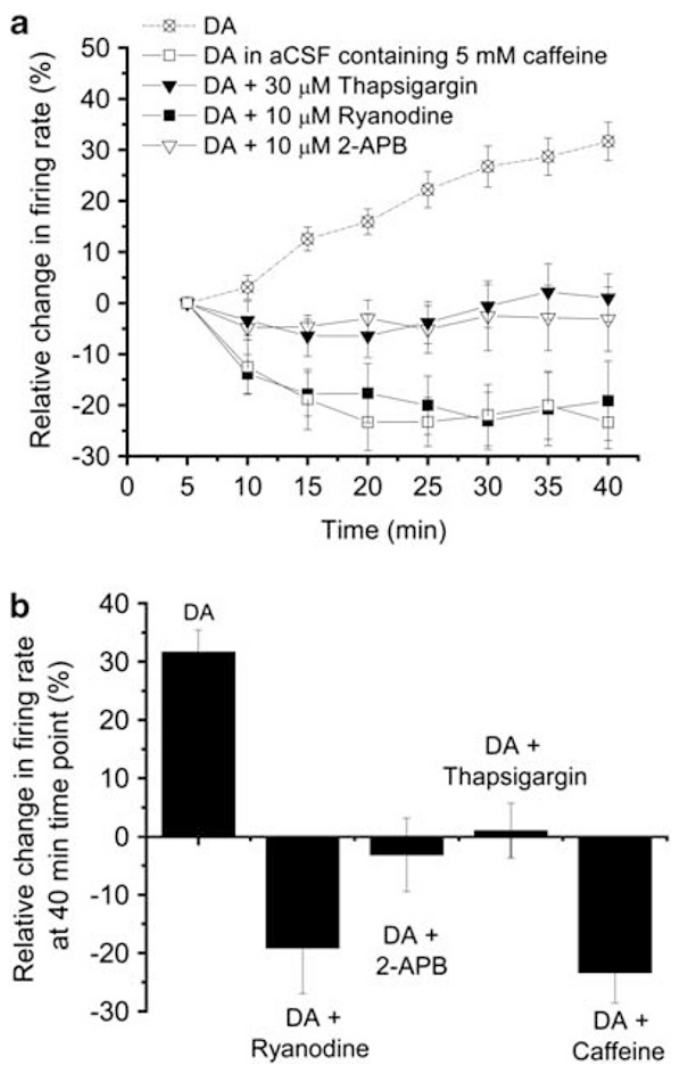

Figure 5 Effects of inhibition of calcium release from intracellular store on long-duration dopamine (DA) application. (a) Relative change in firing rate (mean $\pm \mathrm{SEM}$ ) is plotted as a function of time. Effect of DA at each time point was normalized by subtracting the change in firing rate (\%) at the 5 min time point. The response to a concentration of DA that produced reversal of DA-induced inhibition (from Figure I) is shown for reference (open symbols and dashed line). A concentration of DA that produced more than $60 \%$ inhibition at 5 min time point was applied for $40 \mathrm{~min}$. In the presence of inositol 1,4,5-triphosphate (IP3) receptor inhibitor 2-aminoethoxydiphenyl borate (2-APB; $10 \mu \mathrm{M}, \nabla)$, there was no significant change in the inhibition produced by DA ([DA] $=6.0 \pm 1.0 \mu \mathrm{M}, n=5)$ over the $40 \mathrm{~min}$ time course (one-way repeated measures analysis of variance (ANOVA), $F=0.26, P>0.05)$. In the presence of the ryanodine receptor inhibitor ryanodine $(\boldsymbol{\square}, 10 \mu \mathrm{M})$, a significant increase in DA-induced inhibition ( $[D A]=7.5 \pm 1.12 \mu \mathrm{M}, n=6$ ) was observed (one-way repeated measures ANOVA, $F=4.43, P<0.0 \mathrm{I})$. In the presence of caffeine $(5 \mathrm{mM}$, $\square$ ), a significant increase in DA-induced inhibition ([DA] $=4.2 \pm 0.8 \mu \mathrm{M}$, $n=5$ ) was observed over the $40 \mathrm{~min}$ time course (one-way repeated measures ANOVA, $F=9.4, P<0.01$ ). In the presence of thapsigargin $(\boldsymbol{\nabla}, 30 \mu \mathrm{M}$ in pipette), there was no significant change in the inhibition induced by $D A([D A]=6.0 \pm 1.3 \mu \mathrm{M}, n=5)$ over the 40 min time course (one-way repeated measures ANOVA, $F=1.76, P>0.05$ ). (b) Comparison of relative change in firing rate (mean \pm SEM) at the last time point.

( $30 \mu \mathrm{M}$ in the recording pipette, $n=5$; one-way repeated measures ANOVA, $\mathrm{F}_{(7,28)}=1.76, P>0.05$; Figure 5a).

The results at the last time point from Figure $5 \mathrm{a}$ were summarized in a single bar graph as shown in Figure 5b. A significant inhibition reversal was observed when DA was applied alone, but not when DA was co-applied with ryanodine, 2-APB, thapsigargin, or caffeine. These results support the importance of calcium release from the intracellular store for the reversal of DA-induced inhibition.

As there is evidence that calcium release from the intracellular store can trigger the influx of calcium from 
the extracellular medium (Meldolesi et al, 1992; Sah et al, 1993), we determined the contribution of dihydropyridinesensitive $\mathrm{Ca}^{2+}$ channels and store-operated calcium channels. In these experiments, the test drugs were added to the microelectrode filling solution instead of the external medium. The recordings in which drug was added to the micropipette were maintained for $20 \mathrm{~min}$ before DA was tested to permit sufficient time for the drug to diffuse from the pipette onto the target cells. When a $40 \mathrm{~min}$ application of DA $(n=10)$ was tested with voltage-gated calcium channel blocker nifedipine $(10 \mu \mathrm{M})$ present in the filling solution, there was a significant reduction in the magnitude of DA inhibition over the time course (repeated measures ANOVA, $\left.\mathrm{F}_{(7,56)}=17.71, P<0.01\right)$, indicating that nifedipine did not antagonize DIR (Figure 6a). In contrast, when an inhibitor of store-operated calcium entry (SOCE) SKF96365 $(100 \mu \mathrm{M})$ was included in the microelectrode filling solution, DA inhibition reversal was blocked $(n=8$; repeated measures ANOVA, $\mathrm{F}_{(7,49)}=0.14, P>0.05$; Figure 6a). Therefore, the reversal is dependent on calcium from SOCE, but not on voltage-gated dihydropyridine-sensitive calcium channels.

To reinforce these findings, the development of DIR was assessed in external medium containing a low calcium $(0.24 \mathrm{mM})$ concentration. DA was added stepwise in increasing concentrations until inhibition of firing was $50 \%$ or greater compared with baseline. In low calcium medium, DA $(n=10)$ inhibited firing and the magnitude of inhibition did not change significantly over $40 \mathrm{~min}$ (repeated measures ANOVA, $\mathrm{F}_{(7,63)}=0.64, \quad P>0.05$; Figure $6 \mathrm{a})$. This result supports the contention that DIR requires external calcium.

To emphasize the importance of extracellular calcium on DA inhibition reversal, the results at the last time point from Figure 6a were summarized in a single bar graph as shown in Figure $6 \mathrm{~b}$. DA alone produced a significant inhibition reversal at $40 \mathrm{~min}$ time point, and nifedipine did not antagonize the reversal of DA-induced inhibition. In low calcium buffer or in the presence of SKF96365, however, the firing rate at $40 \mathrm{~min}$ time point was not significantly different from the $5 \mathrm{~min}$ time point.

\section{DA Inhibition Reversal: Age-Dependence}

The results described above indicate that DIR is dependent on PKC and both extracellular calcium concentration and intracellular calcium release. The dependence on calcium suggests that a conventional PKC mediates DIR. It has been demonstrated in the rat that different isoforms of $\mathrm{PKC}$ are present in different amounts during postnatal development. At birth, $\mathrm{PKC} \alpha$ and $\operatorname{PKC} \beta$ are present in the brain and increase rapidly to reach stable levels at 14 days postnatally; in contrast, $\mathrm{PKC} \gamma$ is not present in the brain at birth and is at very low levels for the first 2 weeks, and only reaches a stable level at 3-4 weeks postnatally (Hashimoto et al, 1988; Yoshida et al, 1988). We assessed DIR in pDA VTA neurons in brain slices of F344 rat pups of 12-18 days postnatal age. The results of these experiments are shown in Figure 7. At ages $12(n=10), 13(n=8)$, and $14(n=12)$ days postnatally, DA inhibition did not reverse for the duration of the 40 min DA exposure. A significant inhibition in firing rate was observed from $15-40 \mathrm{~min}$ time points compared with
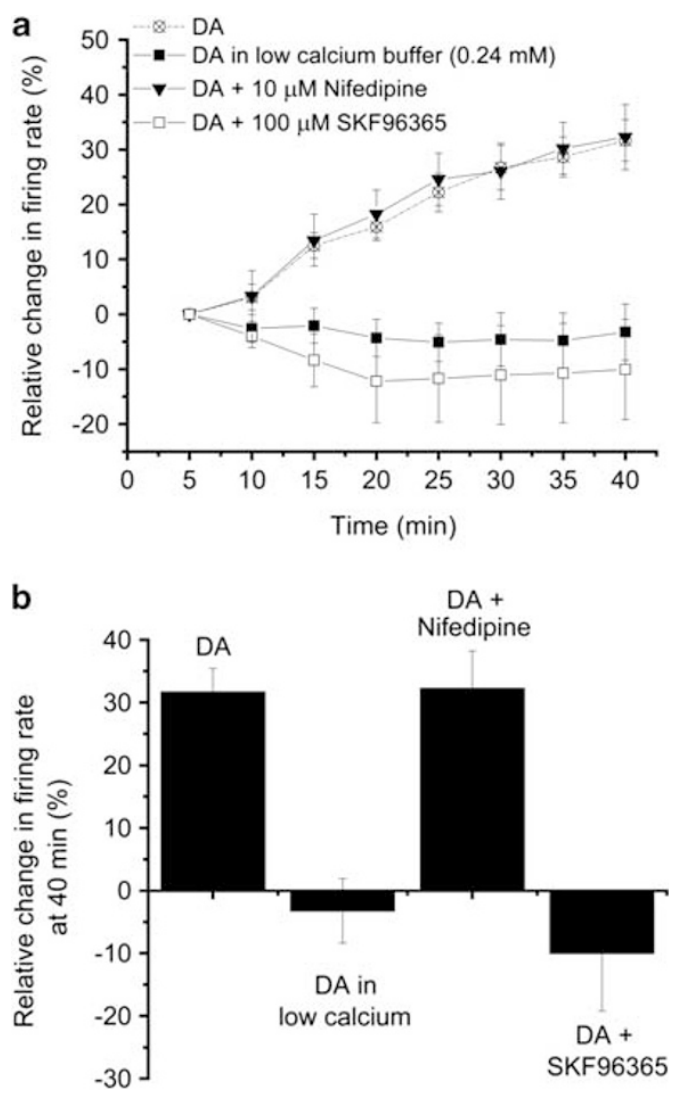

Figure 6 (a) Effects of inhibition of calcium influx from extracellular medium on long-duration dopamine (DA) application. Relative change in firing rate (mean $\pm \mathrm{SEM}$ ) is plotted as a function of time. Effect of DA at each time point was normalized by subtracting the change in firing rate (\%) at the 5 min time point. The response to a concentration of DA that produced reversal of DA-induced inhibition (from Figure I) is shown for reference (open symbols and dashed line). Nifedipine or SKF96365 was added to the microelectrode filling solution and these electrodes were used to measure the change in firing rate. After 20 min of recording, a concentration of DA that produced more than $60 \%$ inhibition at the $5 \mathrm{~min}$ time point was applied for $40 \mathrm{~min}$. In the presence of the voltage-gated calcium channel blocker nifedipine $(\boldsymbol{\nabla}, 10 \mu \mathrm{M})$, a significant reduction in DA inhibition over the 40 min time course was observed $([D A]=5.3 \pm 1.1 \mu \mathrm{M}$, $n=10$ ), with the last four time points significantly different from the 10 min time point (one-way repeated measures analysis of variance (ANOVA), $F=17.7 \mathrm{I}, P<0.01$; Tukey's post-hoc test, $P<0.05$ ). In the presence of the store-operated calcium entry (SOCE) inhibitor SKF96365 ( $\square, 100 \mu \mathrm{M})$, there was no significant change in the inhibition induced by DA $([D A]=8.4 \pm 1.2 \mu \mathrm{M}, n=8$ ) over the $40 \mathrm{~min}$ time course (one-way repeated measures ANOVA, $F=1.37, P>0.05$ ). When a concentration of DA that after 5 min produced more than $60 \%$ inhibition was applied for $40 \mathrm{~min}$ in low calcium buffer $\left(\boldsymbol{\square},\left[\mathrm{Ca}^{2+}\right]=0.24 \mathrm{mM}\right)$. No significant reduction in DA -induced inhibition over the $40 \mathrm{~min}$ time course was observed when DA $(6.25 \pm 1.3 \mu \mathrm{M} ; n=10)$ was applied in low calcium buffer (one-way repeated measures ANOVA, $F=0.64, P>0.05$ ). (b) Comparison of relative change in firing rate (mean \pm SEM) at the last time point.

the $5 \mathrm{~min}$ time point in the pups of ages 12 (repeated measures ANOVA, $\mathrm{F}_{(7,63)}=4.05, P<0.01$ ) and 14 (repeated measures ANOVA, $\mathrm{F}_{(7,77)}=5.74, P<0.01$ ) days, but no significant change was observed in the pups of age 13 days (repeated measures ANOVA, $\mathrm{F}_{(7,49)}=1.23, P>0.05$ ). At age 15 days, there was a small, but significant decrease in DA inhibition over time $(n=17)$, and a Tukey's post-hoc comparison indicated a significant difference between rates 


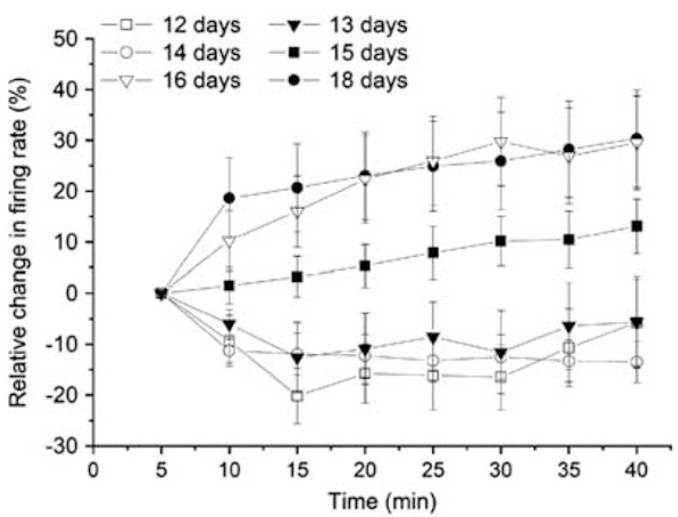

Figure 7 Age-dependence of dopamine (DA) inhibition reversal. The putative dopaminergic (pDA) ventral tegmental area (VTA) neurons in brain slices of rat pups of $12-18$ days postnatal age were examined. Relative change in firing rate (mean $\pm \mathrm{SEM}$ ) is plotted as a function of time. Effect of DA at each time point was normalized by subtracting the change in firing rate (\%) at the $5 \mathrm{~min}$ time point. A concentration of DA that produced more than $60 \%$ inhibition at 5 min time point was applied for $40 \mathrm{~min}$. DA produced a steady (age 13) or increasing (ages 12 and 14) inhibition of firing over the 40 min time course of application in PDA VTA neurons from rat pups ages 12 ( $\square$, one-way repeated measures analysis of variance (ANOVA), $F=4.05, P<0.01), 13(\boldsymbol{\nabla}$, one-way repeated measures ANOVA, $F=1.23, P>0.05)$ and 14 days $(O$, one-way repeated measures ANOVA, $F=5.74, P>0.05)$. At age 15 days postnatally, there was a small but significant reversal in DA-induced inhibition over the $40 \mathrm{~min}$ time course of administration ( $\boldsymbol{\square}$, one-way repeated measures ANOVA, $F=3.89, P<0.01$ ). A significant reversal of $D A$ inhibition was observed in pDA VTA neurons from rat pups ages 16 ( $\nabla$, one-way repeated measures ANOVA, $F=7.62, P<0.01)$ and $18(\bullet$, one-way repeated measures ANOVA, $F=12.05, P<0.01)$ days postnatally.

measured at $5 \mathrm{~min} v s 35$ or $40 \mathrm{~min}$ (one-way repeated measures ANOVA, $\left.\mathrm{F}_{(7,112)}=3.89, P<0.01\right)$. For ages $16(n=12)$ and $18(n=7)$ days, the firing rate was initially inhibited, followed by a significant decrease in DA-induced inhibition over the course of the $40 \mathrm{~min}$ application. There was a significant decrease in DA inhibition at the last three time points compared with the 5 or $10 \mathrm{~min}$ time point for the pups of ages 16 (one-way repeated measures ANOVA, $\mathrm{F}_{(7,70)}=7.62, P<0.01$ ) and 18 (one-way repeated measures ANOVA, $\left.\mathrm{F}_{(7,42)}=12.05, P<0.01\right)$ days.

\section{DISCUSSION}

We have previously reported that extended exposure of pDA VTA neurons to inhibitory concentrations of DA results in a time- and concentration-dependent decrease in response to DA, which required concurrent activation of D2- and D1-like DA receptors (Nimitvilai and Brodie, 2010). Recovery of the sensitivity of pDA VTA neurons after DIR can be up to 90 min (Nimitvilai and Brodie, 2010). Because it requires concurrent stimulation of two different subtypes of DA receptor, it is neither homologous desensitization nor heterologous desensitization, so we termed this phenomenon 'DIR'. The results of this study indicate that this DIR is mediated by PKC, and is also dependent on extracellular calcium concentration and intracellular calcium release, and is age-dependent. In light of the literature on PKC isoforms, the evidence suggests that PKC $\gamma$ is the subtype of PKC that mediates DIR. Many additional studies might be required to conclusively identify this subtype of PKC, such as gene knockout studies, but such studies would require availability of a rat knockout of various PKC isoforms, or establishment of this phenomenon and replication of many of the present results in a mouse strain that would serve as a background for such knockouts. Although the results in rat pups suggest age-dependence of the phenomenon, assessment of PKC $\gamma$ at those ages, beyond what is found in the literature (Hashimoto et al, 1988), would be suggestive, but not conclusive, as many proteins may show age-dependence (Brewer et al, 2007). More detailed studies in the future will be necessary to work out the full molecular mechanism of this phenomenon. This report reveals important information on several factors influencing D2 desensitization in rats, and age-dependence of DIR, that is critical for understanding and exploring this phenomenon.

The results reported here indicate our initial efforts to characterize the mechanism of DIR. Although there are decades of work linking the activation of dopaminergic receptors with adenylyl cyclase and protein kinase A, there is a relatively recent and growing literature on the actions of dopaminergic agonists not related to increases or decreases in cyclic AMP. Future studies will need to investigate the details of the interaction of PKC and the D2 receptor, including whether PKC initiates internalization of the D2 receptor. Interactions between $\mathrm{PKC}$ and DA receptors in the literature has focused on interaction of D1- and D2-like DA receptors (George and O'Dowd, 2007). Co-activation of D1 and D2 receptors results in stimulation of PLC activity, resulting in an increase in intracellular calcium concentration that is dependent on intracellular calcium stores, but not on extracellular calcium (Rashid et al, 2007; So et al, 2009). Concurrent stimulation of D5 and D2 receptors, on the other hand, increase intracellular calcium by mechanisms that require both extracellular calcium and calcium from intracellular stores (So et al, 2009). Increases in intracellular calcium evoked by stimulation of D5-D2 heteromeric receptors was not reduced by nifedipine, but was blocked by the SOCE inhibitor SKF96365 (So et al, 2009), similar to our results with DIR. As evidence suggests that D5 receptors (Khan et al, 2000; Ciliax et al, 2000) and D2 receptors (Sesack et al, 1994) are present on dopaminergic neurons of the VTA, and we show here that DIR requires both intracellular and extracellular calcium, the data in this paper are consistent with the literature on interaction of D1- and D2-like receptors on pDA VTA neurons.

It must be underscored here that interaction of D1- and D2-like receptors in our studies does not imply or support a direct interaction within individual pDA VTA neurons between those two receptor types. As intriguing as the possibility of D1- and D2-like receptor interaction on pDA VTA neurons may be, many other possibilities for interactions between D2 receptors and PKC may be responsible for DIR. For example, $\alpha-1$ adrenergic (Nabekura et al, 1996) and neurotensin (Thibault et al, 2011) receptors can activate PKC and are present on pDA VTA neurons, and neurotensin can cause desensitization of D2 receptors. Although the agonist concentrations used in these experiments would not activate either receptor, there may be more complex interactions at the level of signal transduction that could account for our observations. As all of our observations 
were made in $400-\mu \mathrm{m}$-thick brain slices, the possibilities for interactions among neurons within the slice, including GABAergic interneurons and glutamatergic terminals, is not only possible, it is likely. This includes the possibility that D1 agonists increase glutamate release in the VTA brain slice, as has been demonstrated (Deng et al, 2009); the glutamate could, in turn, activate metabotropic glutamate receptors, which have been demonstrated to affect intracellular calcium (Morikawa et al, 2000). This is only one of the many possible interactions of DA agonists with other neurons within the VTA. Many more experiments will be necessary to determine the exact cellular mechanisms induced by D1- and D2-like interactions.

A role for PKC in desensitization of D2 receptors has been reported in many systems such as HEK293 cells, and striatal and hippocampal neurons (Namkung and Sibley, 2004; Bofill-Cardona et al, 2000; Thibault et al, 2011; Lee et al, 2004; So et al, 2005; Rashid et al, 2007). In experiments employing site-directed mutagenesis, two PKC phosphorylation sites have been identified in the third intracellular loop of the D2 receptor. Activation of PKC in HEK293T cells caused phosphorylation of D2 receptors, resulting in desensitization and internalization of those receptors; activation of PKA had no effect on the phosphorylation state of D2 receptors (Namkung and Sibley, 2004). Additional studies in the VTA will be needed to establish the mechanisms by which reduction in D2 function occurs during DIR, and whether known mechanisms, such as the involvement of $\beta$-arrestin and dynamin (Thibault et al, 2011), contribute to the desensitization.

In general, in control experiments, the antagonists used in this study had no significant effects on their own over the period equivalent to the $40 \mathrm{~min}$ DA agonist application period (Table 1). One exception was BIS-I, which produced a small but significant change in firing rate. The reasons may be related to the spectrum of action of BIS-I, which can also antagonize $\mathrm{PKC} \delta$ and $\mathrm{PKC} \varepsilon$ at concentrations 10-fold higher than those that block conventional PKCs (Toullec et al, 1991), whereas Gö6976 has more selectivity for conventional PKC isoforms (Martiny-Baron et al, 1993). The other antagonist that altered the firing rate in a timedependent manner was thapsigargin, which alters internal calcium release by interfering with the $\mathrm{Ca}^{2+}$ ATPase, producing an increase in cytosolic calcium (Treiman et al, 1998), which may be the cause of the significant increase in firing rate. Ryanodine and 2-APB, on the other hand, had no significant time-dependent effect on firing rate, and neither of these drugs produces a rise in internal calcium (Sutko et al, 1997; Peppiatt et al, 2003). Our results in rat pups suggest that there is a minimum age at which DIR is expressed. While clearly seen at 16 days postnatally, it was not observed at ages of 14 days postnatally or younger (Figure 7). Information from the literature indicates that there are developmental differences in the amounts of different PKC isoforms present in rat brain. For conventional PKC isoforms in whole brain, an early study was unable to detect the $\gamma$-isoform of PKC at ages younger than 2 weeks in Sprague-Dawley rats (Hashimoto et al, 1988). Another study showed that whole brain PKC $\gamma$ levels increase later than those of other conventional PKCs, reaching $<25 \%$ of the adult level by 14 days, whereas $\mathrm{PKC} \alpha$ and $\mathrm{PKC} \beta$ are nearly to their adult levels at 14 days
(Yoshida et al, 1988). Examination of mRNA expression in rat brain indicate that different isoforms of PKC are expressed heterogeneously in various brain areas, and that there are changes (increases and decreases) between postnatal days 7 and 21 of conventional PKCs in most brain regions that were examined (Minami et al, 2000). Additional studies will be required to determine whether the age-dependent expression of DIR in F344 rat pups is related to the developmental emergence of $\mathrm{PKC} \gamma$, another PKC isoform, or other proteins integral to DIR.

When quinpirole was tested in the presence of forskolin or 8-bromo-cAMP, the mean concentrations of quinpirole required to produce $>50 \%$ inhibition were greater (72 and $60 \mathrm{nM}$, respectively) than those needed in the presence of PMA $(35 \mathrm{nM})$ or under control conditions $(40 \mathrm{nM})$ (Figure 2). We previously reported that much higher concentrations of quinpirole alone $(3 \mu \mathrm{M})$ are needed to observe DIR, and this DIR is also blocked by D1 antagonists (Nimitvilai and Brodie, 2010). In the case of forskolin and 8-bromo-cAMP in this study, moderately higher concentrations of quinpirole may have been required due to an action of increased protein kinase A activity on D2 sensitivity. Desensitization of D1 receptors can be at least partly mediated by protein kinase A phosphorylation of the D1 receptor (Jiang and Sibley, 1999). However, in HEK293T cells PKC, not protein kinase A, caused desensitization of D2 receptors (Namkung and Sibley, 2004). Detailed additional studies could determine whether D2 receptors in the VTA can be phosphorylated by either protein kinase A or PKC, or whether phosphorylation of the D2 receptor, D5 receptor, or both receptors, occurs via protein kinase A and can lead to decreased sensitivity of D2 receptors.

The literature suggests some involvement of calcium in interactions between D1- and D2-like receptors that involve PLC-mediated increases in intracellular calcium in HEK293 cells (Lee et al, 2004) and brain neurons (Lee et al, 2004; Rashid et al, 2007). We show here participation of PLC in mediating DIR in PDA VTA neurons. PLC was shown to be involved in D5-D2 hetero-oligomer-induced increases in intracellular calcium (So et al, 2009). In addition, it has been shown that neurotensin, which activates PLC via Gq (Grisshammer and Hermans, 2001), can cause desensitization of D2 receptors (Thibault et al, 2011), and this is consistent with our observation that PLC is involved in the mediation of DIR. Activation of PLC results in the formation of IP3 and DAG from PIP2, and can produce increases in PKC activity as well as increases in intracellular calcium concentration (Nishizuka, 2001). Phosphorylation of D2 receptors by PKC is critical for the mechanism of desensitization of D2 receptors (Thibault et al, 2011). Co-activation of D5-D2 receptors on pDA VTA neurons likely results in the activation of PKC and increase in intracellular calcium necessary for phosphorylation of D2 receptors that accounts for the decreased inhibition of firing that we observe during DIR. Future studies will be needed to determine whether the D5-D2 receptor interaction in pDA VTA neurons results in internalization of $\mathrm{D} 2$ receptors as a result of the action of PKC (Namkung and Sibley, 2004), or if phosphorylation mediates desensitization through a novel mechanism.

Increases in DA signaling in response to psychomotor drugs like cocaine have been documented for decades 


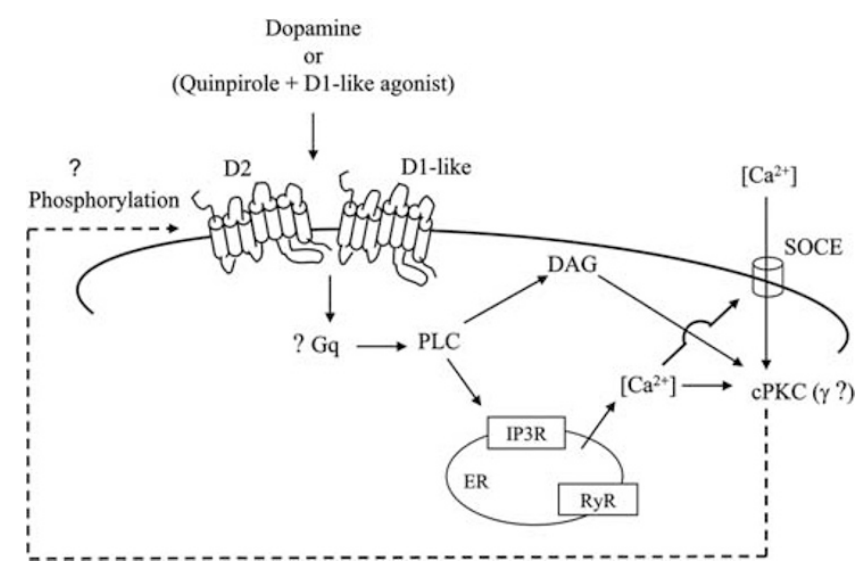

Figure 8 Possible mechanism underlying the reversal of dopamine (DA) inhibition of putative dopaminergic (pDA) ventral tegmental area (VTA) neurons. Concurrent stimulation of D2- and DI-like receptors causes an activation of phospholipase C (PLC) (probably through Gq-mediated mechanism), resulting in increases in diacylglycerol (DAG) and inositol 1,4,5-triphosphate (IP3) formation. Calcium release from the intracellular stores is induced by IP3 receptor activation, which triggers an influx of calcium through the store-operated calcium entry (SOCE). The activated DAG and the increase in intracellular calcium stimulate conventional PKC (cPKC), possibly the $\gamma$-isoform, which may further phosphorylate D2 receptors, decreasing D2-mediated inhibition.

(see Sulzer (2011) for a review). The results presented here indicate that DIR can occur at much lower concentrations of DA in the presence of $100 \mathrm{nM}$ cocaine than with DA alone. As the $\mathrm{EC}_{50}$ of cocaine for monoamine transporters is between $10^{-7}$ and $10^{-6} \mathrm{M}$ (Hill et al, 2009), low concentrations of cocaine may increase the likelihood that DA in the VTA can cause activation of PKC, and subsequently decrease responsiveness to DA autoinhibition. This would result in less autoregulation, and excitatory inputs to the VTA would produce more increases in firing and more DA release in terminal fields receiving DA innervation. The linkage in the literature between increased DA and reward/reinforcement indicate that DIR could augment the reinforcing efficacy of drugs like cocaine by reducing autoinhibition produced by DA release in the VTA. These results support the possible mechanism underlying the reversal of DA inhibition that is shown in Figure 8; it should be noted here that the D1-like receptor could be located on a pre-synaptic terminal of, for example, a glutamatergic neuron, which would result in the same cascade depicted in this figure. Co-activation of D2- and D1-like receptors causes activation of PLC (probably through a Gq-mediated mechanism; Grisshammer and Hermans, 2001), which in turn results in increases in DAG and IP3. IP3 acts to release calcium from intracellular stores and this also triggers an increase in SOCE. Both the IP3 receptor and the ryanodine receptor are important for controlling intracellular calcium levels in pDA VTA neurons (Morikawa et al, 2000). The increase in DAG, coupled with an increase in intracellular calcium, results in the activation of PKC, likely the $\gamma$-isoform, which in turn phosphorylates D2 receptors, decreasing D2-mediated inhibition (Figure 8). The involvement of Gq, the identification of the precise PKC isoform, and the nature of the phosphorylation event mediated by PKC remain to be fully characterized.
Desensitization of D2 DA receptors on DA neurons of the VTA is likely to have important ramifications on the excitability of these neurons, and would have consequences on information processing related to reward and reinforcement (Schultz, 2010). Drugs like cocaine increase extracellular DA concentrations and can cause activation of D2 receptors on pDA VTA neurons (Brodie and Dunwiddie, 1990). One effect of this may be to desensitize D2 receptors, resulting in less autoinhibition. In addition, cocaine can cause a transient increase in $\alpha$-amino-3-hydroxyl-5-methyl4-isoxazole-propionate (AMPA)-induced currents through redistribution or phosphorylation of existing AMPA receptors (Ungless et al, 2001; Saal et al, 2003); phosphorylation of AMPA receptors can be mediated by PKC (McDonald et al, 2001). Furthermore, phosphorylation of $N$-methyl-Daspartate (NMDA) receptors related to long-term potentiation (LTP) in the VTA can be mediated by PKC (Luu and Malenka, 2008). It is possible that cocaine-induced increases in extracellular DA activate PKC through D5 and D2 receptor stimulation, and this activated PKC may phosphorylate AMPA and/or NMDA receptors, resulting in LTP. As all drugs of abuse can increase extracellular DA (Wise, 1996; Di Chiara and Imperato, 1988), activation of D1- and D2-like receptors and induction of a form of LTP may be a common mechanism for long-term effects of abused substances on DA VTA neurons.

\section{ACKNOWLEDGEMENTS}

We thank Maureen McElvain, Laura N Hetue, and Vivek Pandey for excellent technical assistance, and Chayant Tantipathananandh for custom software development and support. We also sincerely thank Dr Robert O Messing for many helpful discussions during the performance of the experiments and the writing of this manuscript. This study was supported by the National Institutes of Health, National Institute on Alcohol Abuse and Alcoholism (PHS Grants AA09125, AA05846).

\section{DISCLOSURE}

The authors declare no conflict of interest.

\section{REFERENCES}

Akita Y, Ohno S, Konno Y, Yano A, Suzuki K (1990). Expression and properties of two distinct classes of the phorbol ester receptor family, four conventional protein kinase $\mathrm{C}$ types, and a novel protein kinase C. J Biol Chem 265: 354-362.

Bian JH, Ghosh TK, Wang JC, Gill DL (1991). Identification of intracellular calcium pools. Selective modification by thapsigargin. J Biol Chem 266: 8801-8806.

Bofill-Cardona E, Kudlacek O, Yang Q, Ahorn H, Freissmuth M, Nanoff C (2000). Binding of calmodulin to the D2-dopamine receptor reduces receptor signaling by arresting the $G$ protein activation switch. J Biol Chem 275: 32672-32680.

Brewer LD, Thibault O, Staton J, Thibault V, Rogers JT, GarciaRamos G et al (2007). Increased vulnerability of hippocampal neurons with age in culture: temporal association with increases in NMDA receptor current, NR2A subunit expression and recruitment of L-type calcium channels. Brain Res 1151: 20-31.

Brodie MS, Dunwiddie TV (1990). Cocaine effects in the ventral tegmental area: evidence for an indirect dopaminergic 
mechanism of action. Naunyn Schmiedebergs Arch Pharmacol 342: 660-665.

Brodie MS, McElvain MA, Bunney EB, Appel SB (1999a). Pharmacological reduction of small conductance calcium-activated potassium current (SK) potentiates the excitatory effect of ethanol on ventral tegmental area dopamine neurons. J Pharmacol Exp Ther 290: 325-333.

Brodie MS, Pesold C, Appel SB (1999b). Ethanol directly excites dopaminergic ventral tegmental area reward neurons. Alcohol Clin Exper Res 23: 1848-1852.

Buck E, Zimanyi I, Abramson JJ, Pessah IN (1992). Ryanodine stabilizes multiple conformational states of the skeletal muscle calcium release channel. J Biol Chem 267: 23560-23567.

Caille I, Dumartin B, Bloch B (1996). Ultrastructural localization of D1 dopamine receptor immunoreactivity in rat striatonigral neurons and its relation with dopaminergic innervation. Brain Res 730: 17-31.

Ciliax BJ, Nash N, Heilman C, Sunahara R, Hartney A, Tiberi M et al (2000). Dopamine $\mathrm{D}(5)$ receptor immunolocalization in rat and monkey brain. Synapse 37: 125-145.

Cragg S, Rice ME, Greenfield SA (1997). Heterogeneity of electrically evoked dopamine release and reuptake in substantia nigra, ventral tegmental area, and striatum. J Neurophysiol 77: 863-873.

Defagot MC, Malchiodi EL, Villar MJ, Antonelli MC (1997). Distribution of D4 dopamine receptor in rat brain with sequence-specific antibodies. Brain Res Mol Brain Res 45: 1-12.

Deng C, Li KY, Zhou C, Ye JH (2009). Ethanol enhances glutamate transmission by retrograde dopamine signaling in a postsynaptic neuron/synaptic bouton preparation from the ventral tegmental area. Neuropsychopharmacology 34: 1233-1244.

Di Chiara G, Imperato A (1988). Drugs abused by humans preferentially increase synaptic dopamine concentrations in the mesolimbic dopamine system of freely moving rats. Proc Natl Acad Sci USA 85: 5274-5278.

Gao C, Wolf ME (2008). Dopamine receptors regulate NMDA receptor surface expression in prefrontal cortex neurons. J Neurochem 106: 2489-2501.

George SR, O'Dowd BF (2007). A novel dopamine receptor signaling unit in brain: heterooligomers of D1 and D2 dopamine receptors. Scient World J 7: 58-63.

Grace AA, Bunney BS (1984). The control of firing pattern in nigral dopamine neurons: single spike firing. J Neurosci 4: 2866-2876.

Grisshammer R, Hermans E (2001). Functional coupling with Galpha(q) and Galpha(i1) protein subunits promotes high-affinity agonist binding to the neurotensin receptor NTS1 expressed in Escherichia coli. FEBS Lett 493: 101-105.

Guerreiro S, Marien M, Michel PP (2011). Methylxanthines and ryanodine receptor channels. Handb Exp Pharmacol 200: 135-150.

Hashimoto T, Ase K, Sawamura S, Kikkawa U, Saito N, Tanaka C et al (1988). Postnatal development of a brain-specific subspecies of protein kinase C in rat. J Neurosci 8: 1678-1683.

Hill ER, Tian J, Tilley MR, Zhu MX, Gu HH (2009). Potencies of cocaine methiodide on major cocaine targets in mice. PLoS One 4: e7578.

Imperato A, Di Chiara G (1986). Preferential stimulation of dopamine release in the nucleus accumbens of freely moving rats by ethanol. J Pharmacol Exp Ther 239: 219-228.

Imperato A, Mulas A, Di Chiara G (1986). Nicotine preferentially stimulates dopamine release in the limbic system of freely moving rats. Eur J Pharmacol 132: 337-338.

Jiang D, Sibley DR (1999). Regulation of D(1) dopamine receptors with mutations of protein kinase phosphorylation sites: attenuation of the rate of agonist-induced desensitization. Mol Pharmacol 56: 675-683.

Kenakin TP (1987). Analysis of dose-response data. In: Pharmacologic Analysis of Drug-Rreceptor Interaction. Kenakin TP (ed). Raven Press: New York, NY. pp 129-162.
Khan ZU, Gutierrez A, Martin R, Penafiel A, Rivera A, de la CA (2000). Dopamine D5 receptors of rat and human brain. Neuroscience 100: 689-699.

Kim KM, Nakajima Y, Nakajima S (1995). G proteincoupled inward rectifier modulated by dopamine agonists in cultured substantia nigra neurons. Neuroscience 69: $1145-1158$

Lacey MG, Mercuri NB, North RA (1987). Dopamine acts on D2 receptors to increase potassium conductance in neurones of the rat substantia nigra zona compacta. J Physiol (Lond) 392: 397-416.

Lacey MG, Mercuri NB, North RA (1989). Two cell types in rat substantia nigra zona compacta distinguished by membrane properties and the actions of dopamine and opioids. J Neurosci 9: 1233-1241.

Lammel S, Hetzel A, Hackel O, Jones I, Liss B, Roeper J (2008). Unique properties of mesoprefrontal neurons within a dual mesocorticolimbic dopamine system. Neuron 57: 760-773.

Lee SP, So CH, Rashid AJ, Varghese G, Cheng R, Lanca AJ et al (2004). Dopamine D1 and D2 receptor co-activation generates a novel phospholipase C-mediated calcium signal. J Biol Chem 279: 35671-35678.

Liu Z, Bunney EB, Appel SB, Brodie MS (2003). Serotonin reduces the hyperpolarization-activated current (Ih) in ventral tegmental area dopamine neurons: involvement of 5-HT2 receptors and protein kinase C. J Neurophysiol 90: 3201-3212.

Luu P, Malenka RC (2008). Spike timing-dependent long-term potentiation in ventral tegmental area dopamine cells requires PKC. J Neurophysiol 100: 533-538.

Margolis EB, Lock H, Hjelmstad GO, Fields HL (2006). The ventral tegmental area revisited: is there an electrophysiological marker for dopaminergic neurons? J Physiol 577: 907-924.

Margolis EB, Mitchell JM, Ishikawa J, Hjelmstad GO, Fields HL (2008). Midbrain dopamine neurons: projection target determines action potential duration and dopamine $\mathrm{D}(2)$ receptor inhibition. J Neurosci 28: 8908-8913.

Martiny-Baron G, Kazanietz MG, Mischak H, Blumberg PM, Kochs G, Hug H et al (1993). Selective inhibition of protein kinase C isozymes by the indolocarbazole Go 6976. J Biol Chem 268: 9194-9197.

McDonald BJ, Chung HJ, Huganir RL (2001). Identification of protein kinase $\mathrm{C}$ phosphorylation sites within the AMPA receptor GluR2 subunit. Neuropharmacology 41: 672-679.

Meldolesi J, Villa A, Podini P, Clementi E, Zacchetti D, D'Andrea P et al (1992). Intracellular $\mathrm{Ca}^{2+}$ stores in neurons. Identification and functional aspects. $J$ Physiol Paris 86: 23-30.

Minami H, Owada Y, Suzuki R, Handa Y, Kondo H (2000). Localization of mRNAs for novel, atypical as well as conventional protein kinase $\mathrm{C}$ (PKC) isoforms in the brain of developing and mature rats. J Mol Neurosci 15: 121-135.

Mirenowicz J, Schultz W (1996). Preferential activation of midbrain dopamine neurons by appetitive rather than aversive stimuli. Nature 379: 449-451.

Morikawa H, Imani F, Khodakhah K, Williams JT (2000). Inositol 1,4,5-triphosphate-evoked responses in midbrain dopamine neurons. J Neurosci 20: RC103.

Mueller AL, Brodie MS (1989). Intracellular recording from putative dopamine-containing neurons in the ventral tegmental area of Tsai in a brain slice preparation. J Neurosci Methods 28: $15-22$.

Nabekura J, Omura T, Horimoto N, Ogawa T, Akaike N (1996). Alpha 1 adrenoceptor activation potentiates taurine response mediated by protein kinase $\mathrm{C}$ in substantia nigra neurons. J Neurophysiol 76: 2455-2460.

Namkung Y, Sibley DR (2004). Protein kinase C mediates phosphorylation, desensitization, and trafficking of the D2 dopamine receptor. J Biol Chem 279: 49533-49541. 
Nimitvilai S, Brodie MS (2010). Reversal of prolonged dopamine inhibition of dopaminergic neurons of the ventral tegmental area. J Pharmacol Exp Ther 333: 555-563.

Nishizuka Y (2001). The protein kinase C family and lipid mediators for transmembrane signaling and cell regulation. Alcohol Clin Exp Res 25: 3S-7S.

Peppiatt CM, Collins TJ, Mackenzie L, Conway SJ, Holmes AB, Bootman MD et al (2003). 2-Aminoethoxydiphenyl borate (2-APB) antagonises inositol 1,4,5-trisphosphate-induced calcium release, inhibits calcium pumps and has a use-dependent and slowly reversible action on store-operated calcium entry channels. Cell Calcium 34: 97-108.

Rashid AJ, So CH, Kong MM, Furtak T, El-Ghundi M, Cheng R et al (2007). D1-D2 dopamine receptor heterooligomers with unique pharmacology are coupled to rapid activation of $\mathrm{Gq} / 11$ in the striatum. Proc Natl Acad Sci USA 104: 654-659.

Saal D, Dong Y, Bonci A, Malenka RC (2003). Drugs of abuse and stress trigger a common synaptic adaptation in dopamine neurons. Neuron 37: 577-582.

Sah P, Francis K, McLachlan EM, Junankar P (1993). Distribution of ryanodine receptor-like immunoreactivity in mammalian central nervous system is consistent with its role in calciuminduced calcium release. Neuroscience 54: 157-165.

Schultz W (2010). Dopamine signals for reward value and risk: basic and recent data. Behav Brain Funct 6: 24.

Sesack SR, Aoki C, Pickel VM (1994). Ultrastructural localization of $\mathrm{D} 2$ receptor-like immunoreactivity in midbrain dopamine neurons and their striatal targets. J Neurosci 14: 88-106.

So CH, Varghese G, Curley KJ, Kong MM, Alijaniaram M, Ji X et al (2005). D1 and D2 dopamine receptors form heterooligomers and cointernalize after selective activation of either receptor. Mol Pharmacol 68: 568-578.

So CH, Verma V, Alijaniaram M, Cheng R, Rashid AJ, O'Dowd BF et al (2009). Calcium signaling by dopamine D5 receptor and D5-D2 receptor hetero-oligomers occurs by a mechanism distinct from that for dopamine D1-D2 receptor heterooligomers. Mol Pharmacol 75: 843-854.
Stanwood GD, Artymyshyn RP, Kung MP, Kung HF, Lucki I, McGonigle P (2000). Quantitative autoradiographic mapping of rat brain dopamine D3 binding with [(125)I]7-OH-PIPAT: evidence for the presence of D3 receptors on dopaminergic and nondopaminergic cell bodies and terminals. J Pharmacol Exp Ther 295: 1223-1231.

Sulzer D (2011). How addictive drugs disrupt presynaptic dopamine neurotransmission. Neuron 69: 628-649.

Sun X, Milovanovic M, Zhao Y, Wolf ME (2008). Acute and chronic dopamine receptor stimulation modulates AMPA receptor trafficking in nucleus accumbens neurons cocultured with prefrontal cortex neurons. J Neurosci 28: 4216-4230.

Sutko JL, Airey JA, Welch W, Ruest L (1997). The pharmacology of ryanodine and related compounds. Pharmacol Rev 49: 53-98.

Thibault D, Albert PR, Pineyro G, Trudeau LE (2011). Neurotensin triggers dopamine D2 receptor desensitiz. J Biol Chem 286: 9174-9184.

Toullec D, Pianetti P, Coste H, Bellevergue P, Grand-Perret T, Ajakane $\mathrm{M}$ et al (1991). The bisindolylmaleimide GF 109203X is a potent and selective inhibitor of protein kinase C. J Biol Chem 266: 15771-15781.

Treiman M, Caspersen C, Christensen SB (1998). A tool coming of age: thapsigargin as an inhibitor of sarco-endoplasmic reticulum $\mathrm{Ca}(2+)$-ATPases. Trends Pharmacol Sci 19: 131-135.

Ungless MA, Whistler JL, Malenka RC, Bonci A (2001). Single cocaine exposure in vivo induces long-term potentiation in dopamine neurons. Nature 411: 583-587.

Wise RA (1996). Neurobiology of addiction. Curr Opin Neurobiol 6: $243-251$

Yoshida Y, Huang FL, Nakabayashi H, Huang KP (1988). Tissue distribution and developmental expression of protein kinase $\mathrm{C}$ isozymes. J Biol Chem 263: 9868-9873.

Zimanyi I, Buck E, Abramson JJ, Mack MM, Pessah IN (1992). Ryanodine induces persistent inactivation of the $\mathrm{Ca}^{2+}$ release channel from skeletal muscle sarcoplasmic reticulum. Mol Pharmacol 42: 1049-1057. 